\title{
Independent effects of grazing and tide pool habitats on the early colonisation of an intertidal community on western Antarctic Peninsula
}

\author{
V. Segovia-Rivera ${ }^{1}$ and N. Valdivia ${ }^{1,2^{*}}$
}

\begin{abstract}
Background: Prevailing environmental conditions can modulate the structuring role of biotic interactions. In intertidal habitats, less stressful environmental conditions and/or higher grazer densities may allow grazing effects to be stronger in tide pools than on emergent rocks. To test this hypothesis, we conducted a manipulative experiment on an intertidal rocky shore in Fildes Bay, King George Island, in which the effect of the dominant grazer Nacella polaris on the structure of benthic periphyton communities was compared between emergent rock and tide pool habitats. Also, we determined the spatial variation in density, weight, and maximum length of individuals of $\mathrm{N}$. polaris in both habitats.

Results: The density of $\mathrm{N}$. polaris was significantly larger in tide pools than on emergent rocks. Contrarily, we observed no significant differences in morphological parameters of $\mathrm{N}$. polaris between both habitats or between intertidal elevations. In the manipulative study, we observed a greater taxonomic richness, diversity, and abundance of periphyton on emergent rocks than in tide pools. These variables also showed, in comparison with control areas, significantly higher values in experimental areas where herbivores were excluded by means of stainless-steel fences. The effects of habitat and grazer exclusion treatments were independent of each other, as no statistically significant interaction between both factors was observed.

Conclusions: Our results showed significant, but independent, effects of tide pool habitats and grazing on the early colonisation of these assemblages. Albeit the grazing effects of other herbivores such as amphipods and small gastropods cannot be ruled out, we suggest that traits of N. polaris, such as high mobility and circadian activity, allow this species to exert a firm control on the intertidal Antarctic assemblages across local environmental conditions.
\end{abstract}

Keywords: Antarctica, Environmental stress model, Grazing, Herbivory, Intertidal, Nacella polaris, Periphyton

\section{Background}

The interplay between biotic interactions and environmental factors is gaining higher relevance in basic and applied ecology, due to the rapid environmental changes that can be observed worldwide (e.g. [1]). The Antarctic

\footnotetext{
* Correspondence: nelson.valdivia@uach.cl

'Laboratorio de Ecología Litoral, Instituto de Ciencias Marinas y Limnológicas, Facultad de Ciencias, Universidad Austral de Chile, Campus Isla Teja, Valdivia, Chile

${ }^{2}$ Centro de Investigación: Dinámica de Ecosistemas Marinos de Altas Latitudes (IDEAL), Universidad Austral de Chile, Campus Isla Teja, Valdivia, Chile
}

ecosystems are showing the world's fastest responses to climate change, but the study of biotic interactions in these habitats has lagged behind other ecosystems [2] The Antarctic intertidal habitats are constantly exposed temperate regions $[5,6]$. Accordingly, biotic interactions like competition, predation, and herbivory can be 
intensified in these microhabitats [7]. The analysis of the effects of biotic interactions on community structure across environmental conditions in Antarctica can be helpful to inform predictive models on how these fragile ecosystems will change in the near future.

Herbivory is defined as the effects that animals cause on populations and communities of plants, and is considered one of the most important ecological processes in marine and terrestrial environments [8-12]. In marine systems, herbivores can determine the spatial and temporal distribution of algae in both intertidal and subtidal habitats, as they can also affect the succession of entire benthic communities [8]. Theoretical models predict that the effects of herbivory and other interactions heavily depend on prevailing environmental stress levels, and it is expected that consumer activity of predators and herbivores should decrease when they are subjected to high environmental stress $[7,13]$. In intertidal systems, which are generally characterised by prevailing harsh conditions for marine organisms due to exposure to atmospheric conditions, habitat heterogeneity in terms of crevices and tide pools provides ameliorated environmental conditions and shelter for a suite of organisms [14]. Accordingly, intertidal herbivores have been shown to have significant effects on the structure of tide pool communities, especially by controlling the abundance of fast-growing, nutrient-limited macroalgae (e.g. [14-16]).

Along intertidal and shallow subtidal Antarctic shores, the gastropod Nacella polaris (hereafter referred to as Nacella) is likely the most abundant grazer in terms of biomass on the Antarctic Peninsula and adjacent islands [17]. This herbivore is adapted to conditions of low temperatures and even freezing to which is exposed during winter [18]. In the Antarctic coast, the populations of Nacella are divided into a fraction that remains submerged in the subtidal habitat and another that migrates during summer months to the intertidal habitat $[19,20]$. The seasonal migration of Nacella matches the recolonisation of the intertidal zone by algal assemblages after ice retreat [21]. Therefore, it is likely that the migration activity of Nacella species is related with a higher resource availability and lower exploitation competition in the intertidal zone during the austral summer.

In Antarctic shores and elsewhere, the re-colonisation of the intertidal zone begins with the arrival of benthic microalgae (e.g. diatoms and cyanophytes) and macroalgal spores; these early colonists are collectively called periphyton [22]. Periphyton is one of the main sources of food for benthic herbivores and in many cases is critical for the establishment of benthic macroalgae [23]. Grazing often has negative effects on the biomass accrual and productivity of this group [24]. In Antarctic coast, intertidal Nacella feeds on periphyton that is mainly comprised by microalgae and small filamentous algae [17]. Although herbivores play an important role in determining algal composition and biomass in intertidal pools elsewhere [11, 14, 25], there has been little attention to the grazing activity on different intertidal habitats on western Antarctic Peninsula (but see [26]).

In this work, we test the hypothesis that less stressful environmental conditions and/or higher grazer densities may result in that grazing effects are intensified in tide pools, which has significant consequences for the recolonisation of benthic communities. From this hypothesis, we deduced the predictions that (1) tide pools should harbour higher densities and larger individuals of the herbivore Nacella, and (2) that the grazing effect of Nacella on the dynamic of periphyton communities is stronger in tide pools than on emergent rocks. The study was conducted on an intertidal rocky shore at Fildes Bay, King George Island, Antarctica. The information of biotic interactions across environmental conditions could be helpful to understand the processes structuring the natural communities in dynamic environments such as the Antarctic intertidal habitat.

\section{Methods}

\section{Study sites and model species}

The study was conducted on an intertidal rocky shore located northeast of Fildes Bay, King George Island (62.18 S, 58.88 W; Fig. 1), and took place between December 2013 and February 2014; in situ observations and samplings were conducted during diurnal low-tide periods. Tide pools in the study site are of ca. eight meters long, showing temperatures and salinity values ranging between 9.3 and $11.2^{\circ} \mathrm{C}$ and 34 and $35 \mathrm{psu}$, respectively.

The study area is characterised by red macroalgae such as Iridaea cordata and crustose algae, which are found

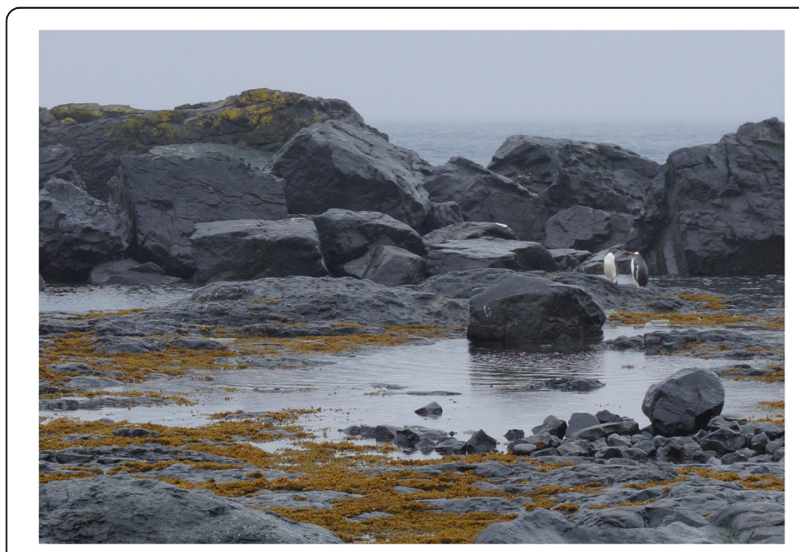

Fig. 1 Study site in NE Fildes Bay, King George Island, Antarctica. The photo was taken during low tide. The dominant macroalgal species around the tide pool in the centre of the picture is Adenocystis utricularis (brown alga). Photo credit: Lilian Villanueva 
mainly in tide pools; Adenocystis utricularis, brown seaweed that is mainly distributed on emergent rock and mid-high intertidal elevations; and the filamentous algae Urospora penicilliformis and Ulothrix sp., which occur in higher abundance in emergent rock habitats (Additional file 1: Figure S1). The assemblage of invertebrate species is dominated by Nacella, followed by the small-sized littorinid snails Laevilittorina antarctica and Laevilacunaria umbilicata.

The study consisted of two parts, an observational study and a manipulative experiment. In the observational study we determined the spatial patterns of occurrence and body size of Nacella as functions of shelter availability (i.e. emergent rock vs. tide pools) and intertidal elevations (i.e. mid- and low intertidal zones). In the manipulative experiment we tested the interactive effect of grazer removal and tide pool habitats on the dynamics of periphyton communities.

Tidal elevation was determined by using the green alga Ulothrix sp. and the red alga Pyropia endiviifolia, as indicators of the upper limit of the intertidal zone [27]. The low limit of the intertidal zone was defined according to chart datum. Once the upper boundary was determined on the shore, we divided the intertidal range in three zones of equal vertical extent (high, mid-, and low zones). Samplings of Nacella were restricted to the midand low intertidal zones, because of the lack of individuals at higher elevations.

\section{Observational study}

For each intertidal height (i.e. mid- and low intertidal zones), ten individuals were collected from haphazardly selected tidal pools and ten from emerging rocks. The organisms were labelled and transported to the laboratory at the Base Antártica Julio Escudero (INACH), where wet weight $(0.001 \mathrm{~g}$ precision $)$ and maximum shell length (0.01 mm precision) were determined.

Density of Nacella was quantified in a 12-m alongshore transect placed in the mid-intertidal zone. The number of Nacella individuals was quantified in $0.25 \times$ $0.25 \mathrm{~m}$ quadrats placed every $0.5 \mathrm{~m}$ along the transect. Also, the percentage cover of tide pools in each quadrat was estimated.

\section{Manipulative experiment \\ Experimental design and setup}

We used a randomized block design to distribute a $2 \times 3$ factorial experiment with "habitat" (two levels: tide pool or emergent rock) and "treatment" (three levels: total exclusion, control, and procedural control) as fixed and crossed factors. In the study site, we haphazardly located four blocks. In each block, we haphazardly selected a tide pool and an area of emergent rock (ca. $1 \mathrm{~m}^{2}$ ). In each tide pool and emergent rock area, we haphazardly located three areas of $0.20 \times 0.20 \mathrm{~m}$. The small size of the experimental area (i.e. experimental unit) was chosen to minimise the impact on the natural assemblages. Each area was randomly assigned to one of the following three treatments: (1) total exclusion (TE), in which a stainlesssteel fence of $20 \times 20 \times 8 \mathrm{~cm}$ (width, length, and height) was fixed to the rock with stainless screws to exclude grazers; (2) control (C), in which the area was delimited with screws in order to allow the access to grazers; and (3) procedural control (PC), in which the experimental area was fenced on two sides in order to allow grazers to access the plot, and at the same time, to generate the potential effects of fencing on confounding factors (Fig. 2). Before installing fences, each plot was scraped with a paint scraper and a steel brush in order to remove macroalgae and mobile invertebrates. Crustose algae were not removed due to logistical constraints.

In the centre of each treatment, we fixed to the substrate with a stainless screw a $10 \times 10 \mathrm{~cm}$ polyvinyl chloride (PVC) plate. On top of this plate, we used Velcro (TM) to fix a set of four small plates of equal size ("sub-plates" hereafter). The surface of each sub-plate was roughened (grain size 60) in order to benefit the settlement of periphyton. In addition, the edges of plates and sub-plates were grinded in order to form a ramp that allowed the grazers to access the plates. Each subplate was replaced every ten days, after completing four sampling times.

\section{Sampling}

In the laboratory at Base Antártica Julio Escudero, settled periphyton was extracted from each sub-plate by means of $4 \%$ formalin and a sterilised tooth brush [23]. The sub-plate was hydrated with $0.5 \mathrm{ml}$ of $4 \%$ formalin, and then the periphyton was extracted by gently scraping with horizontal, vertical, and circular movements the surface of the sub-plate with the brush. This procedure was repeated three times for each sub-plate. A dropper was used to drip onto the plate additional $0.5 \mathrm{ml}$ of $4 \%$ formalin, and then to transfer the material to a $10 \mathrm{ml}$ flask. The samples were subsequently transferred to the Laboratorio de Ecología Litoral, UACH (Valdivia), for further processing.

Periphyton samples $(10 \mu \mathrm{l})$ were poured on a Neubauer chamber and observed under an epifluoresence microscope $(60 \mathrm{x})$. Periphyton taxa were identified to the lowest level possible (genus) on the basis of morphological characteristics. The identification was made using taxonomic descriptions [28-32]. We used species (genus)-accumulation curves to determine the minimum number of sub-samples for each sub-plate-the number of taxa stabilised at four sub-samples. Each periphyton taxon was quantified in one sector of the Neubauer camera and then algal concentration was calculated as: 


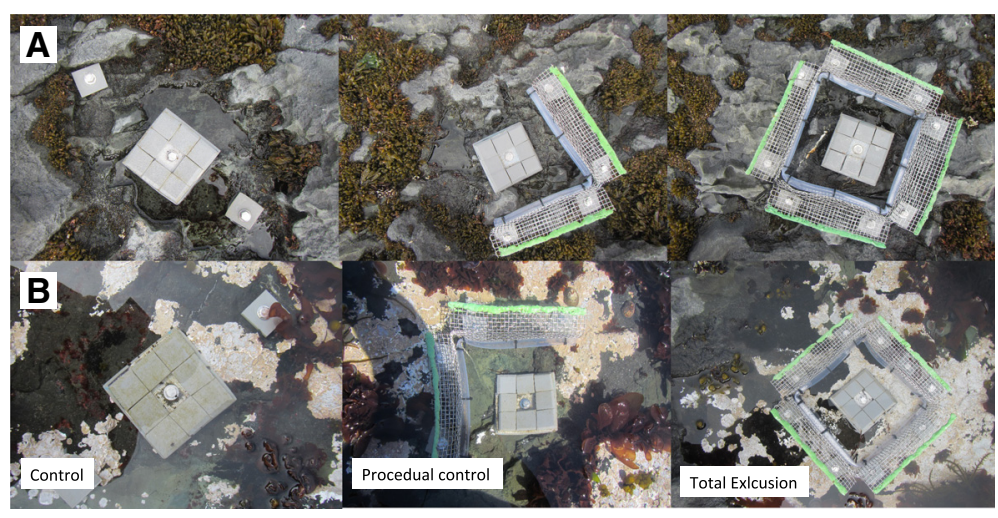

Fig. 2 Experimental setup. Control, procedural control, and herbivore total exclusion treatments were deployed in tide pools (panels a) and on emergent rocks (panels $\mathbf{b}$ )

Algal concentration $\left(\right.$ cells ml $\left.{ }^{-1}\right)=($ Total cells counted in sector $\times 10,000) /$ number of sectors. Taxon richness (i.e. the number of genus in each experimental unit) and diversity were then calculated from the genus abundance data. Diversity was expressed as the Shannon' diversity index $\mathrm{H}$, which combines taxon richness the relative abundance of taxonomic identities. A higher value of the index indicates a greater taxonomic diversity.

\section{Statistical analyses}

Nacella' body weights $(\mathrm{g})$ and lengths $(\mathrm{cm})$ were analysed separately using two-way Analyses of Variance (ANOVA) in the $\mathrm{R}$ environment v. 3.1.2 [33]. The analysis included intertidal zone (either mid- or low zone) and habitat (either emergent rock or tide pool) as crossed and fixed factors. The assumptions of homogeneity of variances were tested through Levene's tests. In addition, we assessed the correlation between Nacella' density and the percentage cover of tide pools by means of a Cross Correlation Function (CCF) analysis in R. In this way, we were able to analyse the spatial structure of Nacella as a function of the availability of tide pools.

For periphyton taxonomic richness and diversity, we separately calculated the area under the curve (AUC) of the relationship between each dependent variable ( $y$ axis) with time ( $\mathrm{x}$-axis). In this way, we integrated each dependent variable over time, avoiding the problems of autocorrelation in the repeated measures. In addition, this transformation allowed us to describe and compare among experimental groups the temporal patterns in species colonisation. For example, and since all plots started from a clean surface, larger AUCs indicated faster re-colonisation patterns. Then, we used a mixedmodel ANOVA to determine the separate and interactive effects of treatments (fixed factor with three levels: TE, C, or PC), habitat (fixed factor; either emergent rock or tide pool), and block (random factor) on the temporal trajectories of taxon richness and diversity.
A significant interaction between grazer treatment and habitat would be seen as evidence supporting our prediction that the effects of herbivory are stronger in tide pools than emergent rocks. A Student-Newman-Keuls (SNK) post hoc analysis was used for the treatment factor in order to contrast the exclusion (TE) and control (C) treatments, as well as to determine whether there was an artefact effect of fences (i.e. C vs. PC treatments).

A non-multidimensional metric scaling (MDS), based on Bray-Curtis dissimilarities, was used to display multivariate patterns of abundances of periphyton. In addition, we tested the effects of treatment, habitat, and block on the multivariate structure of periphyton by means of permutational analysis of variance (PERMANOVA) based on Bray-Curtis dissimilarities calculated from the AUC matrix. Finally, an analysis of percentage similarity (SIMPER) for treatment and habitat was performed to determine the relative contribution of taxa to the differences between groups. Multivariate analyses were performed in PRIMER with PERMANOVA software v. $6[34,35]$. All null-hypothesis significance tests were performed with $\alpha=0.05$.

\section{Results \\ Observational study}

Maximum shell length and wet weight of Nacella ranged from 1.5 to $4.6 \mathrm{~cm}$ and 0.5 to $12.8 \mathrm{~g}$, respectively. Body lengths (Fig. 3a) and weights (Fig. 3b) showed similar values between habitats (i.e. tide pools or emergent rocks) and intertidal zones (i.e. low or mid-intertidal zones). Accordingly, the 2-way ANOVA showed no significant effect of habitat and intertidal zone on both body-size variables $(P>0.05)$.

On the other hand, Nacella densities ranged from 0 to 32 ind. $\mathrm{m}^{-2}$ and 0 to 176 ind. $\mathrm{m}^{-2}$ on emergent rocks and in tide pools, respectively. Mean density values were ca. 2 ind. $\mathrm{m}^{-2}$ and ca. 42 ind. $\mathrm{m}^{-2}$ on emergent rocks and in tide pools, respectively. The CCF analysis showed a 


\section{A}

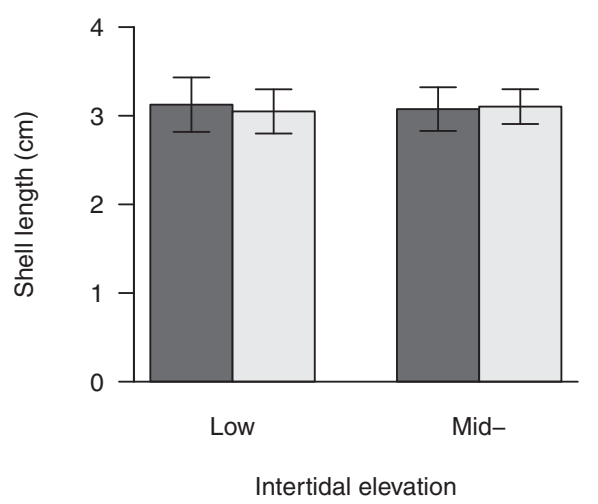

C

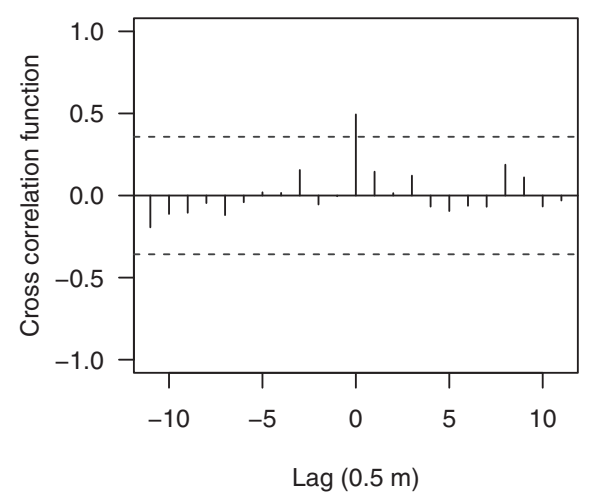

B

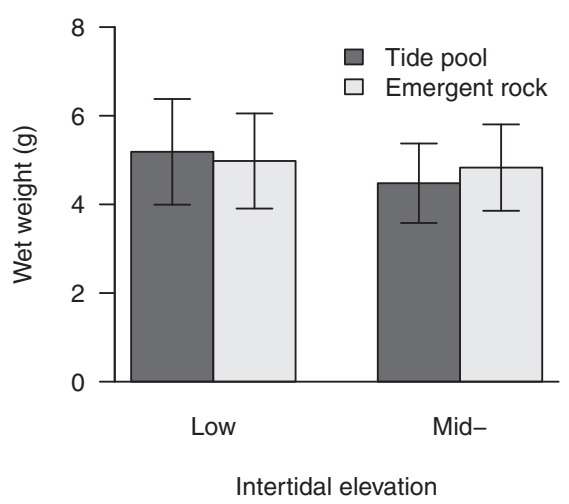

Fig. 3 Morphological parameter and density Nacella. Nacella maximum body length (a) and body weight (b) of Nacella were measured in tide pools and on emergent rocks (dark- and light-grey bars, respectively). In panels $\mathbf{a}$ and $\mathbf{b}$, values are given as means \pm standard errors of the mean (SEM). Panel c shows the cross-correlation between the percentage cover of tide pools ( $x$ ) and density of Nacella (y) in the mid-intertidal zone. In panel $\mathbf{c}$, the height of each bar indicates the correlation estimate at multiple spatial lags between both variables; dotted lines delimit the threshold for statistical significance (Cl $95 \%)$ of correlations

significant and positive correlation between the percentage of cover of tide pools and Nacella' density at lag 0 , indicating a strong "instantaneous" correlation between both variables (Fig. 3c); that is, the density of Nacella was higher in areas with larger tide pool covers.

\section{Manipulative experiment}

We identified a total of eight periphyton taxa (Table 1). Licmophora, Cocconeis, Fragilaria, Actinocyclus, Navicula, and Grammtophora were the first taxa to colonise the settlement panels after ten days of exposure (Table 1). Nitzschia and Amphora colonised the plates after 20 days of colonisation. Recruits of the macroalgae Palmaria (red) and Adenocystis utricularis (brown) were observed after 40 days of exposure to colonisation (Table 1).

Taxon richness peaked after 20 days of colonisation of plates; this peak was lower in tide pools than on emergent rocks (compare Fig. 4a and b). In average, diversity showed an overall decrease after 30 days and a further
Table 1 Periphyton occurrence. Order in which benthic microalgae and macroalgal propagules occurred on settlement plates during the experiment

\begin{tabular}{lllll}
\hline Taxon/Days after start & 10 & 20 & 30 & 40 \\
\hline Licmophora & $\mathrm{x}$ & $\mathrm{x}$ & $\mathrm{x}$ & $\mathrm{x}$ \\
Cocconeis & $\mathrm{x}$ & $\mathrm{x}$ & $\mathrm{x}$ & $\mathrm{x}$ \\
Fragilaria & $\mathrm{x}$ & $\mathrm{x}$ & $\mathrm{x}$ & $\mathrm{x}$ \\
Actinocyclus & $\mathrm{x}$ & $\mathrm{x}$ & $\mathrm{x}$ & $\mathrm{x}$ \\
Navicula & $\mathrm{x}$ & $\mathrm{x}$ & $\mathrm{x}$ & $\mathrm{x}$ \\
Grammatophora & $\mathrm{x}$ & $\mathrm{x}$ & $\mathrm{x}$ & $\mathrm{x}$ \\
Nitzschia & & $\mathrm{x}$ & $\mathrm{x}$ & $\mathrm{x}$ \\
Amphora & & $\mathrm{x}$ & $\mathrm{x}$ & \\
Ulothrix & & & $\mathrm{x}$ & $\mathrm{x}$ \\
Palmaria & & & & $\mathrm{x}$ \\
Adenocystis & & & & $\mathrm{x}$ \\
\hline
\end{tabular}


A

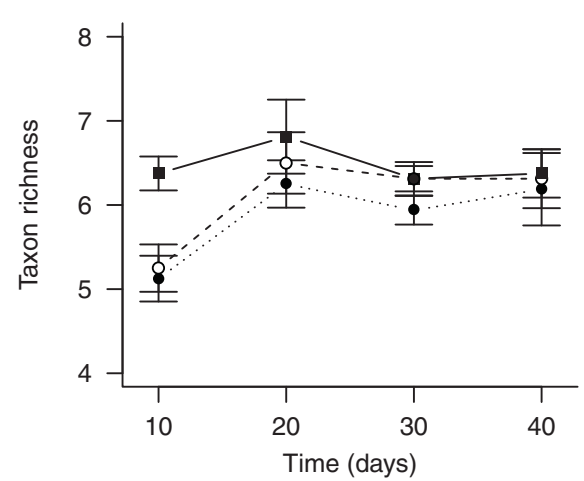

C

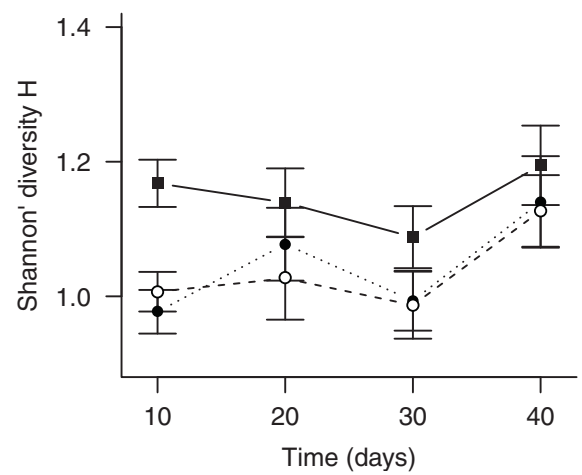

B

Emergent rock

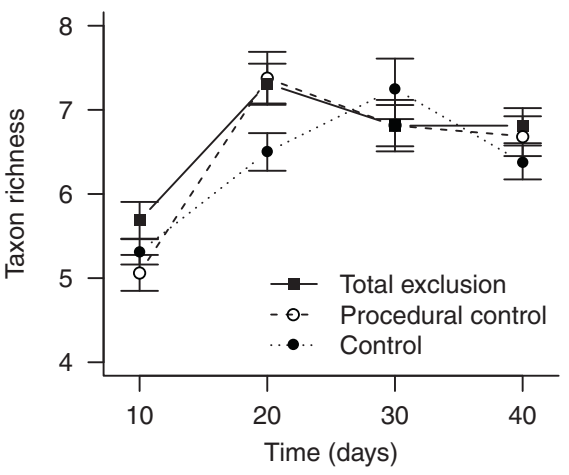

D

Emergent rock

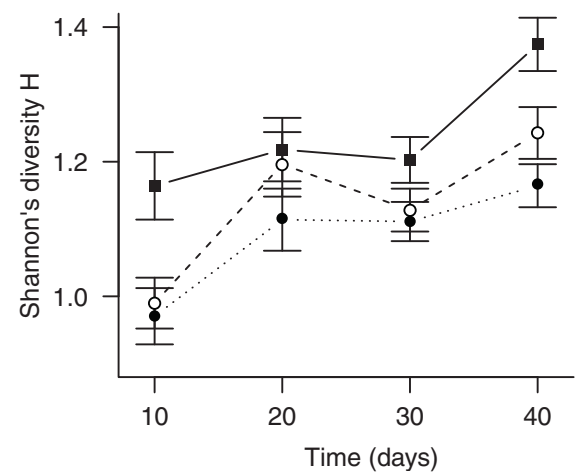

Fig. 4 Temporal patterns of richness $(\mathbf{a}, \mathbf{b})$ and Shannon' diversity $(\mathbf{c}, \mathbf{d})$ during the grazer-exclusion experiment. The experiment was replicated in tide pools $(\mathbf{a}, \mathbf{c})$ and on emergent rocks $(\mathbf{b}, \mathbf{d})$. Values are given as means \pm standard errors of the mean (SEM)

increase after 40 days of colonisation (Fig. $4 \mathrm{c}$ and d). Exclusion treatment and habitat showed significant and independent effects on taxonomic richness and diversity; block accounted for a significant amount of variation in taxon richness (Table 2). Both, control (C) and procedural control (PC) treatments showed significantly lower number of taxa and diversity than the TE treatment (Fig. 4, SNK test: $P<0.05$ ). The differences between the $\mathrm{C}$ and $\mathrm{PC}$ treatments were statistically non-significant for taxonomic richness and diversity (Fig. 4, SNK: $P>$
0.05), indicating that confounding effects of fences on the colonisation patterns can be discarded. Taxonomic richness and diversity were significantly lower in tide pools than on emergent rocks (Fig. 4, Table 2).

The MDS ordination showed that experimental units located in tide pools and on emergent rock were well discriminated in terms of Bray-Curtis dissimilarities (Fig. 5). Within these two groups, the TE treatment clustered in the centre of the ordination, while the $\mathrm{C}$ and PC treatments clustered toward the left side (Fig. 5). In

Table 2 Summary of effects of habitat (either tide pool or emergent rock), grazing treatment (total exclusion, control, and procedural control), and randomly selected blocks on the temporal patterns of taxonomic richness, Shannon's diversity, and the structure of periphyton rocky-shore communities

\begin{tabular}{|c|c|c|c|c|c|c|c|}
\hline \multirow[t]{2}{*}{ Source } & \multirow[t]{2}{*}{ d.f. } & \multicolumn{2}{|c|}{ Taxon richness } & \multicolumn{2}{|c|}{ Shannon's diversity } & \multicolumn{2}{|c|}{ Community structure } \\
\hline & & $\mathrm{F}$ & $P$ & $\mathrm{~F}$ & $P$ & pseudo F & $P$ (perm) \\
\hline Habitat $=\mathrm{H}$ & 1 & 10.501 & 0.005 & 7.252 & 0.017 & 19.257 & 0.001 \\
\hline Treatment $=\mathrm{T}$ & 2 & 6.090 & 0.010 & 7.795 & 0.005 & 10.693 & 0.001 \\
\hline Block & 3 & 17.240 & 0.039 & 16.531 & 0.051 & 6.879 & 0.001 \\
\hline $\mathrm{H} \times \mathrm{T}$ & 2 & 0.991 & 0.400 & 0.319 & 0.731 & 1.396 & 0.252 \\
\hline
\end{tabular}

Residual

15

Taxon richness and Shannon's diversity were analysed with ANOVA; community structure was analysed with PERMANOVA, based on Bray-Curtis dissimilarities 


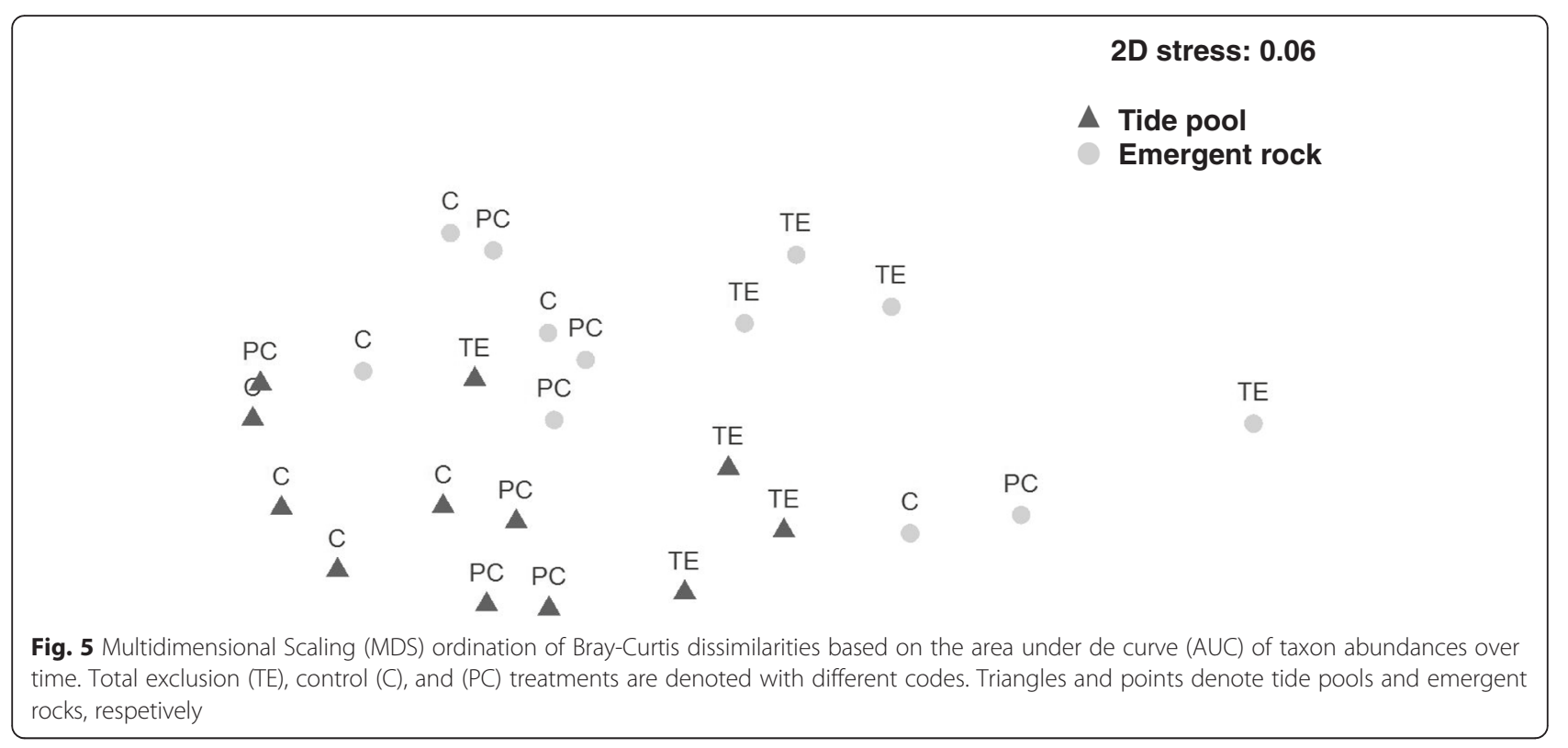

agreement with the univariate analyses (see previous paragraph), the PERMANOVA showed significant responses in community structure to exclusion treatment, habitat, and block, but not to the interaction between habitat and treatments (Table 2). Pairwise multivariate analyses conducted between exclusion treatments showed that the differences between treatments $C$ and PC were statistically non-significant; both control treatments were statistically different from the TE treatment.

According to similarity percentage (SIMPER) analyses, the $92 \%$ of the multivariate differences between tide pools and emergent rocks were accounted for by the genera Navicula, Licmophora, Fragilaria, and Cocconeis. For grazer exclusion treatments, the differences between $\mathrm{TE}$ and $\mathrm{C}$ treatments were accounted for by the genera cited above in addition with Actinocyclus, which together accounted for $94.8 \%$ of the average between-group dissimilarity. For these taxa, we observed higher abundances on emergent rocks than in tide pools, and in TE than $\mathrm{C}$ and $\mathrm{CP}$ treatments.

\section{Discussion}

These results suggest that intertidal tide pool habitats and grazing by the gastropod Nacella polaris (hereafter referred to as Nacella) had significant, albeit independent, effects on the structure of early-succession periphyton communities in a rocky shore on the western Antarctic Peninsula. Individuals of Nacella were found in higher densities in tide pools than on emergent rocks exposed to aerial conditions. Despite these spatial patterns of distribution, body sizes and weights remained similar across microhabitats. In addition, herbivoreexclusion treatments had positive effects on the richness, diversity, and abundances of periphyton taxa, in agreement with previous manipulative work conducted in western Antarctic Peninsula [21,36]. Also, there was a higher richness and diversity of periphyton taxa occurring on emergent rock than in tide pools. Finally, no significant response of periphyton community structure and diversity to the interactive effect of grazer treatments and habitat was observed. Below we discuss these results in the light of what is known about (1) the high mobility of Nacella, (2) the circadian activity of this species, and (3) the potential effect of other grazers on intertidal community structure on western Antarctic Peninsula.

In this study we observed higher abundances of Nacella, but similar body sizes and shell morphologies, when tide pools were compared with emergent rocks. The comparatively high mobility of this species might explain these patterns. For instance, studies on Signy Island described two Nacella groups: a group that migrates from the subtidal to the intertidal zone during the summer and a group that remain submerged. These two groups are distinguished by the morphology of the shell $[19,20]$. Individuals larger than $20 \mathrm{~mm}$ primarily undergo vertical migration, probably as a method to prevent intraspecific competition in the subtidal zone [37]. In agreement with these patterns, significant differences in shell morphology between intertidal and subtidal Nacella have been described in King George Island [21]. Accordingly, the limpets analysed in our study-which was restricted to intertidal measurements-shared similar morphological conditions and body-size ranges. On the other hand, their comparatively high capacity to disperse at the local scale, reflected by vertical migrations, might allow Nacella individuals to move from benign (i.e. tide pools and crevices) to more adverse (i.e. 
emergent rocks) environments in order to allocate food. Subtidal and intertidal Antarctic limpets move 50 and $17 \mathrm{~cm}$ a day, respectively (Kim), which can be considered relatively high if compared with limpets from temperate regions (e.g. [38]). Further observational and manipulative research in this region should focus on behavioural aspects of Nacella, including homing behaviour and circadian rhythms.

Despite that densities of Nacella were highest in tide pools, the grazing effects of this species on periphyton did not vary between microhabitats. Logistic constraints limited our observations to low tide and daylight hours, so we did not account for distributional patterns of Nacella during high tide and night. Herbivores can have differential activity during day and night, as shown in temperate regions [38]. For instance, in central Chile the pulmonate gastropod Siphonaria lessoni is characterised by diurnal activity, while larger herbivores such as Chiton granosus and Fissurella crassa by nocturnal activity [38]. In addition, predation risk can stimulate nocturnal activity in prey species. In Antarctica the kelp gull Larus dominicanus predominantly feeds in shallow water at low tide and daytime, and the number of seagulls looking for prey significantly increases as the extreme low tide approaches $[39,40]$. Therefore, it might be hypothesised that Nacella shows differential day vs. night activity patterns, which might allow this species to forage on emergent rocks when predation risk is low.

We also observed a higher diversity and abundance of periphyton on emergent rocks than tide pools, irrespectively of the presence or absence of Nacella. Tide pools in the intertidal zone of the Antarctic Peninsula harbour, in addition to Nacella, an abundant assemblage of benthic grazing species. Amphipods that feed on periphyton are abundant in the Antarctic intertidal [41-43], and were numerous in tide pools at the experimental location of this study (V. Segovia-Rivera and N. Valdivia, pers. observations). Interesting, we observed a lower percentage cover of filamentous algae in tide pools than emergent rock (see Additional file 1: Figure S1). In shallow subtidal habitats in the Antarctic Peninsula, moreover, amphipod densities can reach more than 300,000 ind. $\mathrm{m}^{-2}$, which are several orders of magnitude higher than densities recorded elsewhere [44]. Such assemblages show specific habitat-selection behaviours depending non-consumptive effects of shallow subtidal predators and algal host characteristics [45], and can be a major driver of, at least, subtidal macrobenthic assemblages $[46,47]$. According to a global literature review that includes the western Antarctic Peninsula, small grazers like amphipods can have strong and significant effects on the structure of local communities [48]. Accordingly, populations of small meso-grazers associated to intertidal tide pools might have a strong effect on benthic colonisation, and these effects could well be comparable to that of larger grazers.

\section{Conclusions}

In summary, the combination of observational and experimental approaches of our study allowed us to determine significant, but independent, effects of grazing and tide pool habitats on early-successional Antarctic communities. The role of meso-grazers such as amphipods and small littorinid snails should be also considered in order to increase the accuracy of predictive models of intertidal community structure. Nevertheless, we suggest that the comparatively high mobility of Nacella allows this species to strongly control the colonisation patterns of these Antarctic habitats, independently of local environmental conditions. The relevance of understanding how these ecosystems function-especially in the early stages of development-cannot be underestimated.

\section{Additional file}

Additional file 1: Figure S1 Percentage cover of dominant sessile species in King George Island. Percentage covers of each macrobenthic species were estimated in situ in $1550 \times 50 \mathrm{~cm}$ quadrats divided in 25 equal fields. Estimations were conduced on emergent rocks and in tide pools. (DOCX $57 \mathrm{~kb}$ )

\section{Competing interests}

The authors declare that they have no competing interests.

Authors' contributions

VS-R and NV participated in all article; VS-R and NV participated in the design of the study, VS-R conducted the field experiments, VS-R and NV performed the statistical analysis, and VS-R and NV participated in the discussion and conclusions. Both authors read and approved the final manuscript.

\section{Acknowledgements}

This study was financially supported by INACH, PIA-CONICYT, and FONDECYT through grants PR_01-13 to VS-R, ART1101 to NV (CoPI), and 1141037 to NV, respectively. INACH and Armada de Chile crews at Fildes Peninsula provided invaluable field support. Valentina Trincado helped in processing of samples. Comments by Chuck Amsler and an anonymous reviewer greatly improved a previous version of the manuscript. We thank the working group Laboratorio de Ecología Litoral ("Lafkenche-lab") at Universidad Austral de Chile for their support during long hours of fieldwork preparation. While writing, NV was supported by FONDAP-IDEAL grant 15150003. This is the publication number 8 of the ART1101 project "Algas Antárticas" and represents to VS-R' honours thesis (Universidad Austral de Chile, Valdivia, Chile).

Received: 31 October 2015 Accepted: 9 February 2016

Published online: 10 March 2016

\section{References}

1. Ghedini G, Russell BD, Connell SD. Trophic compensation reinforces resistance: herbivory absorbs the increasing effects of multiple disturbances. Ecol Lett. 2015;18:182-7.

2. Barnes DKA, Peck LS. Vulnerability of Antarctic shelf biodiversity to predicted regional warming. Climate Res. 2008;37:149-63.

3. Barnes DKA, Rothery P, Clarke A. Colonisation and development in encrusting communities from the Antarctic intertidal and sublittoral. J Exp Mar Biol Ecol. 1996;196:251-65.

4. Pugh PJA, Davenport J. Colonisation vs. disturbance: the effects of sustained ice-scouring on intertidal communities. J Exp Mar Biol Ecol. 1997;210:1-21. 
5. Menge BA, Lubchenco J, Ashkenas LR, Ramsey F. Experimental separation of effects of consumers on sessile prey in the low zone of a rocky shore in the Bay of Panama: direct and indirect consequences of food web complexity. J Exp Mar Biol Ecol. 1986;100:225-69.

6. Raffaelli D, Hawkins S. Intertidal ecology. London: Chapman \& Hall; 1996. p. 356

7. Menge BA, Sutherland JP. Community regulation: variation in disturbance, competition, and predation in relation to environmental stress and recruitment. Am Nat. 1987;130:730-57.

8. Aguilera MA. The functional roles of herbivores in the rocky intertidal systems in Chile: a review of food preferences and consumptive effects. Revista Chilena de Historia Natural. 2011;84:241-61.

9. Hawkins SJ, Hartnoll RG. Grazing of intertidal algae by marine invertebrates. Oceanogr Mar Biol Ann Rev. 1983;21:195-282.

10. Huntly N. Herbivores and the dynamics of communities and ecosystems. Annu Rev Ecol Syst. 1991;22:477-503.

11. Lubchenco J, Gaines SD. A unified approach to marine plant-herbivore interactions. I. Populations and communities. Annu Rev Ecol Syst. 1981;12:405-37.

12. Schmitz OJ. Herbivory from individuals to ecosystems. Annu Rev Ecol Evol Syst. 2008;39:133-52

13. Scrosati RA, van Genne B, Heaven CS, Watt CA. Species richness and diversity in different functional groups across environmental stress gradients: a model for marine rocky shores. Ecography. 2011;34:151-61.

14. Noel L, Hawkins SJ, Jenkins SR, Thompson RC. Grazing dynamics in intertidal rockpools: connectivity of microhabitats. J Exp Mar Biol Ecol. 2009;370:9-17.

15. Methratta ET. Top-down and bottom-up factors in tidepool communities. J Exp Mar Biol Ecology. 2004;299:77-96.

16. Nielsen KJ. Bottom-up and top-down forces in tide pools: test of a food chain model in an intertidal community. Ecol Monogr. 2001;71:187-217.

17. Picken GB. The distribution, growth, and reproduction of the Antarctic limpet Nacella (Patinigera) concinna (Strebel, 1908). J Exp Mar Biol Ecol. 1980;42:71-85

18. Obermuller BE, Morley SA, Clark MS, Barnes DKA, Peck LS. Antarctic intertidal limpet ecophysiology: a winter-summer comparison. J Exp Mar Biol Ecol. 2011:403:39-45.

19. Nolan CP. Size, shape and shell morphology in the Antarctic limpet Nacella concinna at Signy Island, South Orkney Islands. J Molluscan Stud. 1991;57:225-38.

20. Walker AJM. Introduction to the ecology of the Antarctic limpet Patinigera polaris (Hombron and Jacquinot) at Signy Island, South Orkney Islands. Brit Antarct Surv Bull. 1972;28:49-71.

21. Kim D. Seasonality of marine algae and grazers of an Antarctic rocky intertidal, with emphasis on the role of the limpet Nacella concinna Strebel (Gastropoda: Patellidae). Bremen: Fachbereich Biologie/Chemie; 2001.

22. Anderson MJ. Effects of patch size on colonisation in estuaries: revisiting the species-area relationship. Oecologia. 1999;118:87-98.

23. Aguilera MA, Navarrete SA, Broitman BR. Differential effects of grazer species on periphyton of a temperate rocky shore. Mar Ecol Prog Ser. 2013;484:63-78.

24. Hillebrand $H$, de Montpellier $G$, Liess A. Effects of macrograzers and light on periphyton stoichiometry. Oikos. 2004;106:93-104.

25. Benedetti-Cecchi L, Bulleri F, Cinelli F. The interplay of physical and biological factors in maintaining mid-shore and low-shore assemblages on rocky coasts in the north-west Mediterranean. Oecologia. 2000;123:406-17.

26. Zacher K, Wulff A, Molis M, Hanelt D, Wiencke C. Ultraviolet radiation and consumer effects on a field-grown intertidal macroalgal assemblage in Antarctica. Glob Chang Biol. 2007;13:1201-15.

27. Valdivia N, Diaz MJ, Holtheuer J, Garrido I, Huovinen P, Gómez I. Up, down, and all around: scale-dependent apatial variation in rocky-shore communities of Fildes Peninsula, King George Island, Antarctica. Plos One. 2014;9:12.

28. Al-Handal AY, Wulff A. Marine benthic diatoms from Potter Cove, King George Island, Antarctica. Botanica Marina. 2008;51:51-68.

29. Al-Handal AY, Wulff A. Marine epiphytic diatoms from the shallow sublittora zone in Potter Cove, King George Island, Antarctica. Botanica Marina. 2008; 51:411-35.

30. Hasle GR, Syvertsen EE. Marine diatoms. In: Tomas CR, editor. Identifying Marine Phytoplankton. Petersburg, Florida: Elsevier Science; 1997. p. 5-38.
31. Horner R, Schrader GC. Relative contributions of ice algae, phytoplankton and benthic microalgae to primary production in nearshore regions of the Beaufort Sea. Arctic. 1982;35

32. Klöser H. Habitats and distribution patterns of benthic diatoms in Potter Cove (King George Island, Antarctica) and its vicinity. Rep Polar Mar Res. 1998;299:95-105.

33. R Core Team. R: a language and environment for statistical computing. Vienna: R Foundation for Statistical Computing; 2014

34. Clarke KR, Gorley RN. PRIMER v6: User Manual/Tutorial. Plymouth: PRIMER-E; 2006

35. Clarke KR, Warwick RM. Change in marine communities: an approach to statistical analysis and interpretation. Plymouth: PRIMER-E Ltd; 2001.

36. Zacher K, Hanelt D, Wiencke C, Wulff A. Grazing and UV radiation effects on an Antarctic intertidal microalgal assemblage: a long-term field study. Polar Biol. 2007;30:1203-12

37. Brethes JC, Ferreyra G, Delavega S. Distribution, growth and reproduction of the limpet Nacella-(Patinigera)-concinna (Strebel 1908) in relation to potential food availability, in Esperanza Bay (Antarctic Peninsula). Polar Biol. 1994;14:161-70.

38. Aguilera MA, Navarrete SA. Distribution and activity patterns in an intertidal grazer assemblage: influence of temporal and spatial organization on interspecific associations. Mar Ecol Prog Ser. 2011:431:119-36.

39. Cadee GC. Shell damage and shell repair in the Antarctic limpet Nacella concinna from King George Island. J Sea Res. 1999:41:149-61.

40. Favero M, Silva P, Ferreyra G. Trophic relationships between the kelp gull and the Antarctic limpet at King George Island (South Shetland Islands, Antarctica) during the breeding season. Polar Biol. 1997;17:431-6.

41. Castilla JC, Rozbaczylo N, Castilla JC, Rozbaczylo N. Rocky intertidal assemblages and predation on the gastropod Nacella (Patinigera) concinna at Robert Island, South Shetland Antarctica. Serie Científica INACH. 1985;a32:65-73.

42. Momo F, Bogazzi E, Duttweller F. Amphipods of Potter Cove: Community composition, biology and growth. In: Ferreyra G, Arntz W, Rinaldi C, Wiencke C, editors. The Potter Cove coastal ecosystem, Antarctica; 1998. p. 144-149

43. Obermuller BE, Karsten U, Pörtner H-O, Abele D. Effects of UV-radiation on oxidative stress parameters in polar marine amphipods, and the role of UVabsorbing mycosporine-like amino acids (MAAs) in their diet. In: Huiskes AHL, Gieskes WWC, Rozema J, Schorno RML, Van der Vries SM, Wolff WJL, editors. Antarctic biology in a global context proceeding of the 8th SCAR International Biology Symposium, Amsterdam; 2003

44. Amsler CD, McClintock JB, Baker BJ. Macroalgal chemical defenses in polar marine communities. In: Amsler CD, editor. Algal chemical ecology. Berlin: Springer Verlag; 2008. p. 91-103.

45. Zamzow JP, Amsler CD, McClintock JB, Baker BJ. Habitat choice and predator avoidance by Antarctic amphipods: the roles of algal chemistry and morphology. Mar Ecol Prog Ser. 2010;400:155-63.

46. Amsler CD, McClintock JB, Baker BJ. Amphipods exclude filamentous algae from the Western Antarctic Peninsula benthos: experimental evidence. Polar Biol. 2012;35:171-7.

47. Amsler CD, McClintock JB, Baker BJ. Chemical mediation of mutualistic interactions between macroalgae and mesograzers structure unique coastal communities along the western Antarctic Peninsula. J Phycol. 2014;50:1-10.

48. Poore AGB, Campbell AH, Coleman RA, Edgar GJ, Jormalainen V, Reynolds PL, Sotka EE, Stachowicz JJ, Taylor RB, Vanderklift MA, Duffy JE. Global patterns in the impact of marine herbivores on benthic primary producers. Ecol Lett. 2012;15:912-22. 